\title{
Pengelolaan Pemangkasan Tanaman Teh (Cammellia sinensis (L.) O. Kuntze) di Unit Perkebunan Bedakah, PT Tambi Wonosobo, Jawa Tengah
}

\author{
Pruning Management of Tea (Camellia sinensis (L.) O. Kuntze) at Unit Perkebunan Bedakah PT. Tambi, \\ Wonosobo, Jawa Tengah
}

\author{
Ghulam Nurul Huda, Sofyan Zaman* dan Supijatno
}

Departemen Agronomi dan Hortikultura, Fakultas Pertanian, Institut Pertanian Bogor (Bogor Agricultural University), Jl. Meranti, Kampus IPB Darmaga, Bogor 16680, Indonesia

Telp.\&Faks.62-251-8629353 e-mail agronipb@indo.net.id

*Penulis untuk korespondensi : thalhah_al_yuda@yahoo.co.id

Disetujui 14 November 2015 /Published online 12 Desember 2015

\begin{abstract}
The apprentice was conducted at Unit Perkebunan Bedakah, PT Tambi, Wonosobo, Central Java from February until June 2013. The assignment composed of several work, did as field worker for one months, as assistant foreman for one month, as assistant block leades for four weeks and assistant of field lead assistant for two weeks. The general objective is to expand knowledge of apprenticeship students about the technical and managerial aspects of the tea plantations, get skills and work experience. Pruning activities attention to the production helm. If the shoots are considered stable production during the dry season the implementation of pruning can be done $100 \%$ in the first semester This year the crop shifts all blocks implement cuts in two semesters. Realization of the trimmed area in one year is not necessarily the same as the plan that has been set at 25\%. Based on the data obtained in the five-year timeframe realization prunings only $17.83 \%$ of the total area crop yield. This is due to several factors that affect the timing of pruning include garden conditions, climate, and manpower.
\end{abstract}

Keywords : tea, pruning, production, productivity

\begin{abstract}
ABSTRAK
Magang ini dilakukan di Unit Perkebunan Bedakah, PT Tambi, Wonosobo, Jawa Tengah dari bulan Februari hingga Juni 2013. Tugas terdiri dari beberapa pekerjaan diantaranya sebagai pekerja lapangan selama satu bulan, sebagai asisten mandor selama satu bulan, sebagai asisten kepala blok selama empat minggu dan asisten kepala bagian kebun selama dua minggu. Tujuan umum adalah untuk memperluas pengetahuan mahasiswa magang tentang aspek teknis dan manajerial perkebunan teh, mengasah keterampilan dan pengalaman kerja. Kegiatan pemangkasan memperhatikan produksi pucuk. Apabila produksi pucuk dianggap stabil pada musim kemarau maka pelaksanaan pemangkasan dapat dilakukan 100 $\%$ di semester I. pada gilir pangkas tahun ini semua blok melaksanakan pemangkasan dalam dua semester. Realisasi luas areal yang dipangkas dalam satu tahun tidak selalu sama dengan rencana yang telah ditetapkan sebesar $25 \%$. Berdasarkan data yang diperoleh dalam kurun waktu lima tahun realisasi pangkasan hanya $17.83 \%$ dari luas areal tanaman menghasilkan. Hal ini dikarenakan beberapa faktor yang mempengaruhi waktu pelaksanaan pemangkasan diantaranya kondisi kebun, iklim, dan tenaga kerja.
\end{abstract}

Kata kunci : pemangkasan, produksi, produktivitas, teh 


\section{PENDAHULUAN}

Tanaman teh berasal dari famili Theaceae, genus Camellia, spesies (Camellia sinensis (L.) O. Kuntze). Tanaman teh merupakan tanaman perkebunan yang termasuk dalam bagian tanaman penyegar (Suwarto dan Octavianty, 2010). Teh yang biasanya dikonsumsi sebagai minuman penyegar diperoleh dari pengolahan pucuk daun tanaman teh. Menurut Setyamidjaja (2000), tanaman teh diperkirakan berasal dari daerah subtropis yaitu daerah di pegunungan Himalaya dan daerah-daerah yang berbatasan dengan Republik Rakyat Cina, India serta Birma. Meskipun berasal dari daerah subtropis namun daerah penyebarannya juga meliputi daerah tropis, dingin dan panas. Daerah pertanaman teh di Indonesia pada umumnya terletak di dataran tinggi meskipun diusahakan pula di dataran rendah. Lingkungan fisik yang paling berpengaruh terhadap pertumbuhan tanaman teh adalah iklim dan tanah sehingga dalam penanamannya harus memperhatikan kedua faktor tersebut (Pusat Penelitian Teh dan Kina, 2006).

Teh merupakan bagian dari komoditas perkebunan yang menyumbang devisa bagi negara. Berdasarkan data Direktorat Jenderal Perkebunan (2012), volume ekspor teh sering mengalami pasang surut. Pada tahun 2009 volume ekspor teh Indonesia masih mencapai 123506 ton dengan nilai ekspor 131457 juta US\$. Tetapi, pada tahun 2008 volume ekspor teh mengalami penurunan menjadi 122452 ton. Perkebunan teh di Indonesia dalam proses budidaya diusahakan oleh Perkebunan Besar Negara (PBN), Perkebunan Besar Swasta (PBS), dan Perkebunan Rakyat (PR). Pada saat ini Indonesia merupakan negara produsen terbesar ketujuh setelah India, Cina, Srilangka, Kenya, Vietnam, dan Turki. Pada tahun 2012 luas areal pertanaman teh di Indonesia mencapai 152217 ha, total produksi mencapai 168053 ton, dan produktivitas mencapai 1586.86 $\mathrm{kg} \mathrm{ha}{ }^{-1}$. Oleh karena itu, usaha peningkatan produktivitas teh harus selalu diperhatikan.

Salah satu upaya teknik budidaya untuk menjaga dan meningkatkan produktivitas tanaman adalah melalui pemeliharaan tanaman dengan cara pemangkasan. Pemangkasan dapat mempertahankan tanaman pada fase vegetatif, merangsang pertumbuhan tunas muda sehingga menghasilkan pucuk lebih banyak, membentuk bidang petik selebar mungkin, mengganti serta mempermudah percabangan tanaman, serta mengurangi luka-luka pada tanaman yang dipangkas (Suwarto dan Octavianty, 2010).

Untuk menyehatkan tanaman, satu bulan sebelum pemangkasan sebaiknya tanaman tidak dipetik. Tujuannya agar tanaman memiliki masa istirahat untuk mengumpulkan cadangan makanan di dalam batang atau akarnya. Dengan demikian tunas akan cepat tumbuh dan masa produktifnya bisa diperpendek, serta kapasitas pangkas menjadi lunak (Ghani, 2002). Kegiatan penelitian ini bertujuan untuk memperluas wawasan, meningkatkan ketrampilan bekerja dan memperoleh pengalaman, baik dalam aspek teknis maupun manajerial pada berbagai tingkatan yang ada di perkebunan, sedangkan secara khusus kegiatan ini bertujuan untuk mempelajari, menganalisis permasalahan, dan kendala yang dihadapi pada setiap proses produksi, terutama dalam aspek pemangkasan teh di perkebunan.

\section{METODE PENELITIAN}

Kegiatan magang yang dilakukan selama 4 (empat) bulan ini mempunyai kegiatan yaitu : pada bulan pertama bertugas sebagai karyawan harian lepas (KHL) atau buruh harian lepas (BHL), seperti halnya karyawan perkebunan yang lainnya juga melakukan pekerjaan seperti pembibitan, pemupukan, pengendalian gulma, pemangkasan, pengendalian hama dan penyakit, pemetikan, pengolahan hasil yang kegiatannya di bawah pengawasan mandor, dan penulis juga membuat jurnal harian kerja.

Pada bulan kedua, tugas yang dilakukan yaitu sebagai pendamping mandor, yang pekerjaannya merencanakan, mengkoordinir, dan mengawasi pekerjaan karyawan, menghitung biaya operasional yang dipakai dalam setiap kegiatan yang dilakukan, membuat jurnal harian, dan menghitung prestasi kerja karyawan. Kegiatan ini di bawah pengawasan asisten atau kepala afdeling.

Pada bulan ketiga dan keempat, tugas yang dilakukan yaitu sebagai pendamping asisten atau pendamping kepala afdeling yang pekerjaannya membantu mengelola dan mengawasi tenaga kerja, menganalisis setiap kegiatan yang dilakukan di tingkat afdeling dan membuat jurnal harian.

Kegiatan magang ini dilaksanakan selama 4 bulan mulai Februari 2013 sampai Juni 2013 di Unit Perkebunan Bedakah, PT. Tambi, Wonosobo, Jawa Tengah.

Data yang dikumpulkan dalam kegiatan magang meliputi data sekunder dan data primer. Adapun data sekunder yang dikumpulkan adalah iklim (10 tahun terakhir), produksi dan produktivitas (5 tahun terakhir), produktivitas berdasarkan umur pangkas, pola pangkasan, kebutuhan HOK pemangkasan berdasarkan umur setelah pangkas. Data Primer yang dikumpulkan 
pada 15 tanaman contoh adalah pengamatan sebelum pemangkasan (tinggi tanaman, diameter bidang petik, kriteria saat pemangkasan), pengamatan saat pemangkasan (tinggi pangkasan, presentase kerusakan akibat pemangkasan, kebutuhan tenaga per hari, luas areal pemangkasan, tipe/jenis pemangkasan, jumlah tenaga kerja, bobot pangkasan), pengamatan setelah pemangkasan dengan mengukur pertumbuhan tunas.

Pengolahan data yang digunakan adalah deskriptif kualitatif dan kuantitatif terhadap data primer dan sekunder. Pengolahan data deskriptif kuantitatif menggunakan rataan, persentase dan uji t-student. Peubah pengamatan diolah pada taraf nyata $5 \%$.

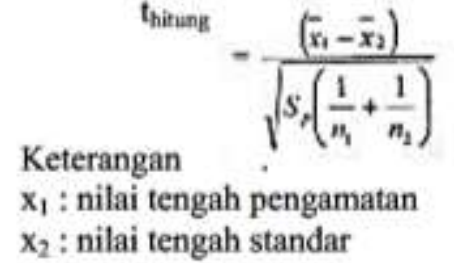

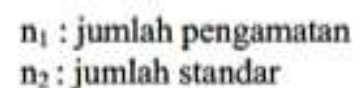

$\mathrm{S}_{1}^{2}$ : ragam pengamatan $\mathrm{S}_{\mathrm{p}}$ : simpangan baku gabungan

Nilai berbeda nyata apabila $t_{\text {hitung }}>t_{\text {tabel }}$ dan tidak berbeda nyata apabila $t_{\text {hitung }}<t_{\text {tabel }} ; t_{\text {tabel }}$ diperoleh dari nilai sebaran t pada taraf $5 \%$ dan $\mathrm{db}\left(\mathrm{n}_{1}+\mathrm{n}_{2}-2\right)$.

\section{HASIL DAN PEMBAHASAN}

\section{Kondisi Umum}

PT. Perkebunan Tambi terdiri dari tiga unit perkebunan yaitu Unit Perkebunan Tambi (UP Tambi), Unit Perkebunan Bedakah (UP Bedakah), Unit Perkebunan Tanjungsari (UP Tanjungsari). Unit perkebunan Bedakah terletak di sebelah barat lereng Gunung Sindoro, Dusun Bedakah, Desa Tlogomulyo, Kecamatan Kertek, Kabupaten Wonosobo, Propinsi Jawa Tengah. Jarak dari ibu kota kabupaten $\pm 17 \mathrm{~km}$ ke arah timur laut Wonosobo. Jarak dari jalan raya menuju unit perkebunan Bedakah $\pm 5 \mathrm{~km}$. unit perkebunan Bedakah berada pada ketinggian 1 200 - $1950 \mathrm{~m} \mathrm{dpl}$.

Curah hujan selama sepuluh tahun terakhir (2003-2012) berkisar 2455 - $4438 \mathrm{~mm}$ dengan ratarata $3031.75 \mathrm{~mm}_{\text {tahun }}{ }^{-1}$ dan hari hujan berkisar 110 - 182 hari dengan rata-rata 149.3 hari hujan tahun $^{-1}$. Iklim berdasarkan curah hujan menurut Schimdt-Ferguson adalah tipe B. Rata-rata bulan kering 2.9 bulan dan rata-rata bulan basah 8.7 bulan.

\section{Luas Areal dan Tata Guna Lahan}

Berdasarkan Rencana Kerja dan Anggaran Pendapatan (RKAP) tahun 2013, luas keseluruhan Unit Perkebunan Bedakah adalah 355.27 ha. Luas areal tanaman menghasilkan (TM) sebesar 285.97 ha yang terbagi dalam enam blok dan luas areal tanaman belum menghasilkan (TBM) 38.17 ha.

\section{Kondisi Tanaman dan Produksi}

Unit perkebunan Bedakah termasuk kebun teh dataran tinggi (high land tea plantation). Komoditas teh yang dihasilkan terdiri atas jenis teh yang berasal dari tanaman teh klonal dan seedling. Jarak tanaman untuk setiap jenis tanaman klon rata-rata 10000 pohon $\mathrm{ha}^{-1}$, sedangkan jenis tanaman seedling 7000 pohon ha ${ }^{1}$. Klon yang dibudidayakan adalah TRI 2024, TRI 2025, Gambung 3, Gambung 4, Gambung 7, Pasir Sarongge, dan TB Merah. Unit Perkebunan Bedakah menggunakan jarak tanam teh $75 \mathrm{~cm} \mathrm{x}$ $140 \mathrm{~cm}$ dan $75 \mathrm{~cm}$ x $100 \mathrm{~cm}$. Produksi teh unit perkebunan Bedakah dalam lima tahun terakhir dapat dilihat pada Gambar 1.

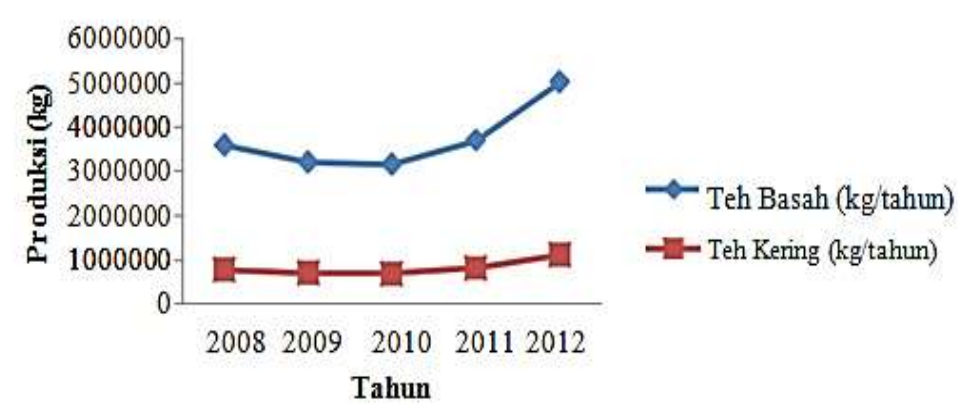

Gambar 1 Produksi basah dan kering tanaman teh tahun 2008-2012 
Berdasarkan data produksi dan produktivitas basah dan kering selama lima tahun terakhir, rata-rata produksi basah $3734000 \mathrm{~kg}$ tahun $^{-1}$ dan produksi kering $817596 \mathrm{~kg}^{\text {tahun }}{ }^{-1}$, produktivitas basah $12616.50 \mathrm{~kg} \mathrm{ha}^{-1}$ sedangkan produktivitas kering $2762.92 \mathrm{~kg} \mathrm{ha}^{-1}$. Produksi teh unit perkebunan Bedakah dalam waktu kurun lima tahun terakhir mencapai $4087978 \mathrm{~kg}$ per tahun.

\section{Tipe Pangkasan}

Tipe pemangkasan memberikan ciri secara kualitatif kepada suatu jenis pemangkasan tentang adanya daun-daun tua yang tersisa di perdu teh setelah pemangkasan selesai. Secara umum pemangkasan bertujuan merangsang pertumbuhan tunas-tunas baru sehingga menghasilkan pucuk dalam jumlah banyak dan berkualitas baik (Suwarto dan Octavianty 2010). Tipe pangkasan produksi yang diterapkan unit perkebunan Bedakah adalah tipe pangkasan bersih.

\section{Tinggi Pangkasan}

Ketinggian pangkasan produksi di unit perkebunan Bedakah adalah $45 \mathrm{~cm}$ sampai $60 \mathrm{~cm}$. Pemangkasan pertama dilakukan pada ketinggian $45 \mathrm{~cm}$ dari permukaan tanah dengan kenaikan setiap pangkasan setinggi $5 \mathrm{~cm}$ dari luka pangkas sebelumnya. Pada tanaman yang tinggi pangkasannya telah mencapai $60 \mathrm{~cm}$ diturunkan lagi pangkasan seperti pangkasan pertama yaitu $45 \mathrm{~cm}$.

Tabel 1. Rata-rata tinggi pangkasan dan diameter bidang pangkas blok Rinjani, Bismo, dan Argopuro

\begin{tabular}{lcccc}
\hline Blok & $\begin{array}{c}\text { Umur } \\
\text { Pangkasan } \\
\text { (Tahun) }\end{array}$ & $\begin{array}{c}\text { Tinggi Pangkasan } \\
\text { Standar }(\mathrm{cm})\end{array}$ & $\begin{array}{c}\text { Tinggi Pangkasan Realisasi } \\
(\mathrm{cm})\end{array}$ & $\begin{array}{c}\text { Diameter Bidang } \\
\text { Pangkas }(\mathrm{cm})\end{array}$ \\
\hline Rinjani & 6 & 50 & $45.3 \pm 0.976$ & $66.3 \pm 5.46$ \\
Bismo & 6 & 50 & $53.2 \pm 1.207$ & $71.3 \pm 4.13$ \\
Argopuro & 4 & 50 & $55.1 \pm 1.187$ & $74.2 \pm 3.86$ \\
\hline
\end{tabular}

Sumber : Hasil Pengamatan (Februari, 2013)

Berdasarkan hasil pengamatan, tinggi pangkasan yang dilakukan oleh tenaga pemangkas blok Bismo, Argopuro dan Rinjani tidak selalu sama dengan standar tinggi pangkasan yang ditetapkan. Faktor yang mempengaruhi perbedaan tinggi pangkasan, umur pangkasan di lapangan, kondisi lahan dan penggunaan alat ukur yang tidak baku. Semakin terampil tenaga pemangkas dan semakin mudah lahan yang dipangkas maka tinggi pangkasan yang dihasilkan akan mendekati standar.

\section{Waktu Pemangkasan}

Penentukan waktu pemangkasan perlu diperhatikan kondisi tanaman dan iklim. Penentuan waktu pemangkasan yang tepat sangat penting untuk menjamin pertumbuhan tanaman berikutnya agar dapat berproduksi secara optimal. Kegiatan pemangkasan di unit perkebunan Bedakah dilaksanakan dua semester. Semester pertama yaitu dilaksanakan pada Februari sampai bulan April dengan luas $60 \%$ dan pada semester II, dilakukan pada bulan Oktober sampai bulan November dengan luas $40 \%$.

\section{Luas Areal Pangkasan}

Unit Perkebunan Bedakah menetapkan luas areal pangkasan per tahun adalah $25 \%$ dari total luas areal tanaman menghasilkan. Waktu pemangkasan di unit perkebunan Bedakah dilakukan dua kali yaitu semester I dan semester II dapat dilihat pada Tabel 2. Luas areal pangkasan disesuaikan dengan luas blok yang dipangkas sehingga total areal yang dipangkas bias lebih atau kurang dari $25 \%$. Seperti yang terlihat di tabel 2 rencana luas areal pangkas dengan rata-rata $23.06 \%$ dari luasan enam blok yang dipangkas. Setiap blok mempunyai kewenangan sendiri dalam pembagian luas areal yang dipangkas. 
Tabel 2. Rencana luas areal pangkas unit perkebunan Bedakah tahun 2013

\begin{tabular}{|c|c|c|c|c|c|}
\hline No & Blok & Nomor Kebun & $\begin{array}{c}\text { Luas Areal } \\
\text { Pangkasan (ha) }\end{array}$ & $\begin{array}{l}\text { Luas Kebun } \\
\text { (ha) }\end{array}$ & $\begin{array}{c}\text { Areal Pangkas } \\
(\%)\end{array}$ \\
\hline 1 & Bismo & 9.10 .11 .14 & 13.75 & 54.96 & 25.02 \\
\hline 2 & Rinjani & 7.11 .12 .13 & 9.28 & 37.20 & 24.95 \\
\hline 3 & Mandala & 5.13 & 10.63 & 52.31 & 20.32 \\
\hline 4 & Argopuro & 8.9.14.13.12 & 14.22 & 48.46 & 29.34 \\
\hline 5 & Kembang & 12.13 & 6.35 & 34.27 & 18.53 \\
\hline \multirow[t]{3}{*}{6} & Muria & 2.3.6.11 & 11.88 & 58.77 & 20.21 \\
\hline & Jumlah : & & 66.11 & 285.97 & 138.37 \\
\hline & Rata-Rata : & & 11.02 & 47.66 & 23.06 \\
\hline
\end{tabular}

Sumber : Kantor kebun unit perkebunan Bedakah, 2013

Apabila produksi pucuk dianggap stabil pada musim kemarau maka pelaksanaan pemangkasan dapat dilakukan $100 \%$ di semester I. pada gilir pangkas tahun ini semua blok melaksanakan pemangkasan dalam dua semester.
Pembagian areal pangkas sebaiknya diatur menurut nomor kebun yang saling berdekatan agar memudahkan dalam dalam pengawasan. Rencana dan realisasi pemangkasan di unit perkebunan Bedakah dapat dilihat pada Tabel 3.

Tabel 3. Bobot basah pucuk dan bobot basah pangkasan

\begin{tabular}{ccccccc}
\hline \multirow{2}{*}{ Tahun } & Luas areal TM (ha) & Rencana & Realisasi & & \multicolumn{2}{c}{ Rersentase (\%) } \\
\cline { 3 - 3 } \cline { 6 - 7 } & & & & & Luas Areal Pangkas (ha) & Realisasi \\
\hline 2008 & 308.23 & 77.55 & 68.09 & & $25.16 \%$ & $22.09 \%$ \\
2009 & 303.05 & 74.39 & 59.54 & & $24.55 \%$ & $19.65 \%$ \\
2010 & 303.42 & 80.47 & 55.70 & & $26.52 \%$ & $18.36 \%$ \\
2011 & 293.50 & 66.66 & 32.29 & & $22.71 \%$ & $11.00 \%$ \\
2012 & 285.49 & 56.42 & 51.48 & & $19.76 \%$ & $18.03 \%$ \\
\hline & Rata-rata & 71.10 & 53.42 & & $23.74 \%$ & $17.83 \%$ \\
\hline
\end{tabular}

Sumber : Kantor kebun unit perkebunan Bedakah, 2013

Realisasi luas areal yang dipangkas dalam satu tahun tidak selalu sama dengan rencana yang telah ditetapkan sebesar $25 \%$. Berdasarkan data yang diperoleh dalam kurung waktu lima tahun realisasi pangkasan hanya $17.83 \%$ dari luas areal Tanaman Menghasilkan. Hal ini dikarenakan beberapa faktor yang mempengaruhi waktu pelaksanaan pemangkasan diantaranya kondisi kebun, iklim, dan tenaga.

\section{Alat Pangkas}

Alat pangkas yang digunakan untuk pemangkasan pada unit perkebunan Bedakah adalah sabit pangkas. kunci utama keberhasilan pemangkasan yaitu ketajaman alat. Alat pangkas yang tajam dapat mengurangi kerusakan cabang hasil pangkasan. Batu asah digunakan untuk mengasah sabit pangkas agar tetap tajam dan halus.

\section{Kriteria saat Pangkas}

Faktor-faktor yang mempengaruhi pelaksanaan pemangkasan antara lain gilir pangkas, ketinggian tanaman, persentase pucuk burung, tingkat produktivitas, kadar pati dan kebijakan kebun.

Gilir Pangkas. Menurut Setyamidjaja (2000), gilir pangkas merupakan jangka antara pemangkas terdahulu dengan pemangkasan berikutnya pada nomor blok yang sama. Panjang pendeknya gilir pangkas dipengaruhi oleh beberapa faktor antara lain ketinggian tempat di atas permukaan laut. Unit Perkebunan Bedakah berada pada ketinggian > $1200 \mathrm{~m}$ dpl termasuk daerah tinggi sehingga daur pangkasnya $4-5$ tahun. Kebijakan unit perkebunan Bedakah menetapkan gilir pangkas empat tahun untuk setiap nomor blok. Namun, pada pelaksanaannya kegiatan pemangkasan tidak selalu sesuai dengan ketentuan karena masih terdapat beberapa nomor blok dengan gilir pangkas 
lima tahun bahkan ada yang enam tahun. Perbedaan gilir pangkas ini disebabkan oleh berbagai hal di lapang secara ekonomis dan teknis menguntungkan perkebunan. Gilir pangkas yang diamati di tiga blok yang diamati dapat dilihat pada Tabel 4.

Tabel 4. Gilir pangkas blok Bismo, Rinjani, dan Argopuro

\begin{tabular}{ccccccc}
\hline Blok & $\begin{array}{c}\text { Nomor } \\
\text { Kebun }\end{array}$ & Luas (ha) & $\begin{array}{c}\text { Waktu } \\
\text { Pemangkasan } \\
\text { Sebelumnya }\end{array}$ & Rencana & Realisasi & $\begin{array}{c}\text { Wilir Pangkas } \\
\text { (tahun) }\end{array}$ \\
\hline Bismo & 7 & 6.06 & Jan 2007 & Jan 2013 & Jan 2013 & 6 \\
& 11 & 2.79 & Feb 2007 & Feb 2013 & Feb 2013 & 6 \\
Rinjani & 8 & 1.66 & Feb 2007 & Feb 2013 & Feb 2013 & 6 \\
Argopuro & 4 & 2.40 & Mar 2009 & Feb 2013 & Feb 2013 & 4 \\
& 7 & 3.13 & Jan 2009 & Jan 2013 & Jan 2013 & 4 \\
\hline
\end{tabular}

Sumber : Kantor kebun unit perkebunan Bedakah, 2013

Tinggi dan diameter bidang petik tanaman. Tinggi bidang petik tanaman diukur dari permukaan tanah sampai pucuk bidang petik. Tabel 5 merupakan data rata-rata tinggi dan diameter bidang petik tanaman sebelem dilakukan pemangkasan pada blok Bismo, Argopuro dan Rinjani.

Tabel 5. Rata-rata tinggi dan diameter bidang petik tanaman sebelum pemangkasan pada blok Bismo, Argopuro, dan Rinjani

\begin{tabular}{lccc}
\hline \multicolumn{1}{c}{ Blok } & $\begin{array}{c}\text { Umur Pangkasan } \\
(\text { Tahun) }\end{array}$ & $\begin{array}{c}\text { Rata-rata Tinggi } \\
\text { Tanaman }(\mathrm{cm})\end{array}$ & $\begin{array}{c}\text { Rata-rata Diameter } \\
\text { Bidang Petik }(\mathrm{cm})\end{array}$ \\
\hline Rinjani & 6 & $113.33 \pm 5.250$ & $87.30 \pm 2.77$ \\
Bismo & 6 & $119.27 \pm 3.863$ & $109.83 \pm 4.08$ \\
Argopuro & 4 & $123.13 \pm 2.615$ & $127.07 \pm 7.42$ \\
\hline Rata-rata & & $118.24 \pm 4.94$ & $108.07 \pm 19.9$ \\
\hline Sumber & $:$ Hasil Pengamatan (Maret, 2013) &
\end{tabular}

Berdasarkan data hasil pengamatan pada Tabel 5, rata-rata ketinggian bidang petik tanaman Blok Bismo, Argopuro dan Rinjani yaitu 118.24 $\mathrm{cm}$ namun diameter bidang petiknya sudah melebar yaitu $108.07 \mathrm{~cm}$. Meskipun tinggi tanaman pada ketiga blok tersebut belum mencapai $120 \mathrm{~cm}$ tetapi tetap dilakukan pemangkasan. Bidang petik yang terlalu lebar akan membuat pemetik kesulitan dalam bergerak karena kerapatan tanaman tinggi dan mempengaruhi produksi teh.

Presentase pucuk burung. Pucuk burung adalah pucuk yang memiliki tunas dalam keadaan dorman. Semakin tinggi umur pangkas, bidang petik semakin lebar, cabang atau ranting yang tidak produktif semakin bertambah sehingga jumlah pucuk muda yang dihasilkan semakin menurun, sedangkan jumlah pucuk burung semakin meningkat.

Tabel 6. Persentase pucuk burung blok Bimo, Argopuro, dan Rinjani

\begin{tabular}{ccc}
\hline & $\begin{array}{c}\text { Umur Pangkasan } \\
\text { (Tahun) }\end{array}$ & \% Pucuk Burung \\
\hline Rinjani & 6 & 79.48 \\
Bismo & 6 & 83.94 \\
Argopuro & 4 & 73.74 \\
\hline Rata-rata & & 79.05 \\
\hline
\end{tabular}

Sumber : Hasil pengamatan (Maret, 2013)

Berdasarkan hasil pengamatan pada blok Bismo, Argopuro dan Rinjani rata-rata persentase pucuk burung mencapai $79.05 \%$ saat mendekati waktu pangkas (Tabel 6). Pada saat kondisi pucuk 
burung tinggi maka kadar pati di akar semakin banyak karena pada saat ini tanaman mengakumulasikan hasil fotosintesis di dalam akar. Semakin tinggi presentase pucuk burung menyebabkan jumlah daun yang memenuhi syarat untuk dipetik menjadi semakin berkurang. Kondisi ini merupakan saat optimum untuk melakukan pemangkasan. Kadar pati dalam akar teh pada daerah tinggi > 1200 mdpl mencapai $25.1 \%$ jika kadar pati kurang dari $12 \%$ biasanya tanaman yang dipangkas akan mati (Sukasman 1988).

Menurut Johan (2006), semakin banyak bagian tanaman yang tidak produktif maka seluruh energi dan suplai hara digunakan untuk menyangga kelangsungan hidup bagian tanaman yang tidak produktif tersebut. Hal ini menyebabkan semakin sedikit energi yang dapat dimanfaatkan tanaman untuk menghasilkan tunas atau pucuk muda sehingga banyak pucuk yang menjadi pucuk burung. Hasil pengamatan pada Blok Bismo, Argopuro dan Rinjani menunjukkan bahwa jumlah pucuk burung telah mencapai $>75$ $\%$.

Bobot pangkasan. Pengamatan dilakukan dengan menimbang bobot basah hasil pangkasan pada 5 tanaman contoh yang diamati pada saat umur setelah tanam. Hasil pengamatan bobot pangkasan dapat dilihat pada Tabel 7 .

Tabel 7. Bobot basah pucuk dan bobot basah pangkasan

\begin{tabular}{ccccc}
\hline Blok & $\begin{array}{c}\text { Umur Pangkasan } \\
(\text { tahun })\end{array}$ & $\begin{array}{c}\text { Tinggi Pangkasan } \\
(\mathrm{cm})\end{array}$ & $\begin{array}{c}\text { Tinggi Tanaman } \\
(\mathrm{cm})\end{array}$ & $\begin{array}{c}\text { Bobot Basah Pangkasan } \\
(\mathrm{kg})\end{array}$ \\
\hline Muria & 5 & 54.55 & 116.10 & $1.11 \mathrm{tn}$ \\
Mandala & 4 & 50.13 & 117.90 & $1.13 \mathrm{tn}$ \\
\hline Sumber : Hasil pengamatan (Mei, 2013) & & &
\end{tabular}

Hasil bobot basah petikan ditentukan oleh jumlah tunas yang terpetik dan bobot per pucuk. Bila pucuk yang terpetik semakin banyak dengan bobot per pucuk yang semakin besar akan menghasilkan bobot hasil petikan yang lebih besar. Pada pangkasan bersih jumlah tunas yang tumbuh sedikit tetapi lebih subur sehingga hampir seluruh tunas dapat mencapai bidang petik (Sukasman 1988). Perhitungan uji t menunjukkan hasil tidak berbeda nyata sehingga dapat dikatakan bahwa bobot pangkasan tidak berpengaruh pada kegiatan pemangkasan.

\section{Tingkat Produktivitas dan Kebijakan Kebun}

Produktivitas tanaman teh suatu blok berkaitan dengan tahun pangkas tanaman. Gambar 2 merupakan grafik produktivitas Unit Perkebunan Bedakah berdasarkan umur pangkas tahun 2012.

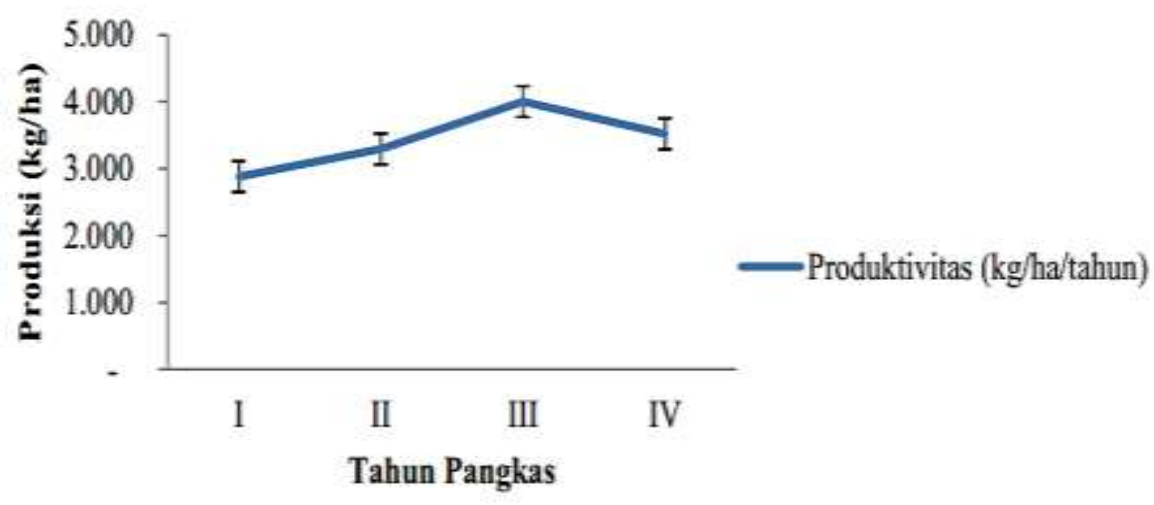

Gambar 2 Grafik produktivitas berdasarkan umur tahun pangkas 2012

Dari grafik produktivitas berdasarkan umur pangkas terlihat pada umur pangkas satu dan dua jumlah produksi pucuk teh mulai meningkat yaitu $2883 \mathrm{~kg} \mathrm{ha}^{-1}$ tahun $^{-1}$ dan $3295 \mathrm{~kg} \mathrm{ha}^{-1}$ $\operatorname{tahun}^{-1}$. Ha ini dikarena tunas-tunas yang baru muncul menghasilkan pucuk yang banyak. Pada umur pangkas ketiga produksi pucuk mencapai titik maksimum mencapai $4002 \mathrm{~kg} \mathrm{ha}^{-1}$ tahun $^{-1}$ dan pada umur pangkas keempat produksi pucuk teh menurun sebesar $12.09 \%$ dari kenaikan sebelumnya atau besar produktivitas $3519 \mathrm{~kg} \mathrm{ha}^{-1}$ tahun $^{-1}$. Hal ini disebabkan dengan bertambahnya umur pangkas tanaman maka bagian yang membutuhkan hasil fotosintat semakin meningkat sehingga ukuran pucuk semakin kecil dan 
bobotnya semakin ringan meskipun rumus petik yang digunakan sama.

Kebijakan kebun dalam menentukan pemangkasan berbeda-beda hal ini dikarenakan kondisi tanaman dan lahan yang berbeda di tiap blok. Kebijakan kebun dalam pemangkasan dapat dilihat pada gambar 3. Diagram tingkat produktivitas berdasarkan tahun pangkas blok Muria, Argopuro dan Rinjani.

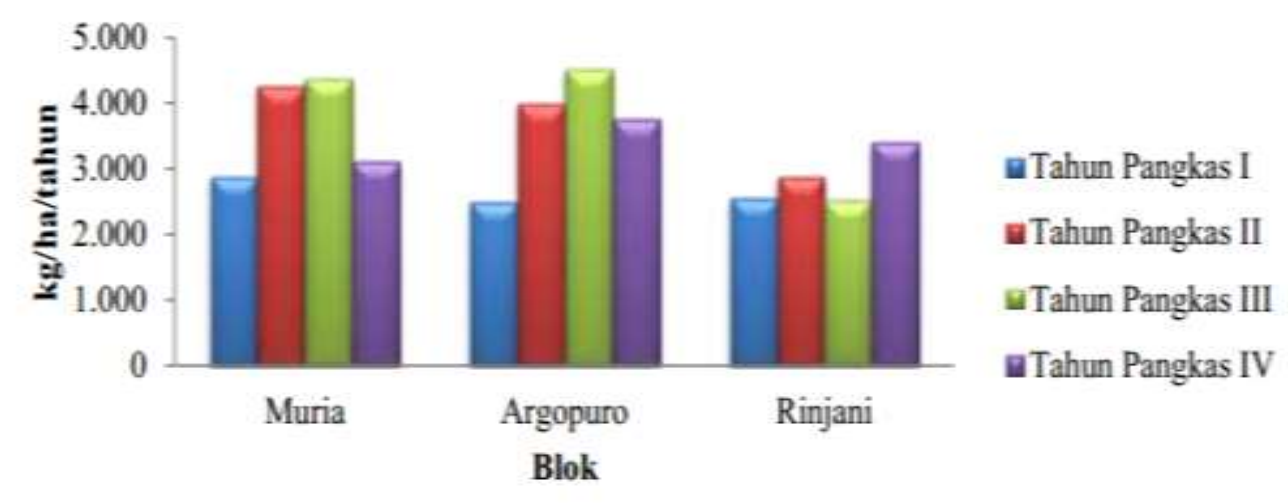

Gambar 3 Diagram produktivitas blok Muria, Argopuro, dan Rinjani berdasarkan tahun pangkas tahun 2012

Berdasarkan gambar 3, blok Muria dan Argopuro memiliki pola diagram produktivitas yang sama. Produktivitas tertinggi dicapai pada tahun pangkas III tetapi tingkat produktivitasnya berbeda. Tingkat produktivitas Blok Argopuro sedikit lebih tinggi yaitu $3697 \mathrm{~kg} \mathrm{ha}^{-1}$ tahun $^{-1}$ dibandingkan dengan produktivitas Blok Muria sebesar $3664 \mathrm{~kg} \mathrm{ha}^{-1}$ tahun $^{-1}$. Hal ini dikarenakan faktor ketinggian tempat yang lebih rendah, sedangkan pada blok muria faktor yang mempengaruhi produktivitas adalah ketinggian tempat yang menyebabkan kelembaban tinggi sehingga pertumbuhan pucuk jika dibandingkan dengan blok argopuro lebih lambat. Pada produktivitas blok rinjani yaitu $2838 \mathrm{~kg} \mathrm{ha}^{-1}$ tahun $^{-1}$, terdapat perbedaan yang mencolok jika dibandingkan dengan blok argopuro dan blok rinjani. Hal ini dikarenakan kesehatan tanaman dilihat dari tahun tanam yang dominan lebih dari 20 tahun.

\section{Keterampilan Pemangkas}

Keterampilan tenaga pemangkasan merupakan aspek kebutuhan teknis yang mempengaruhi kualitas pangkasan tanaman teh. Penulis melakukan pengamatan keterampilan pemangkas berdasarkan lama kerja dan tingkat pendidikan terhadap kerusakan cabang hasil pangkasan. Pengamatan dilakukan terhadap 10 orang tenaga pemangkas yang dibagi menjadi dua kelompok masing-masing 5 orang untuk setiap klasifikasi. Setiap tenaga pemangkas diambil lima tanaman contoh hasil pangkasan. Perhitungan persentase kerusakan cabang dilakukan dengan menghitung jumlah cabang bekas pangkasan yang pecah atau rusak.

Keterampilan Tenaga Kerja Pemangkas Berdasarkan Klasifikasi Lama Kerja. Dalam kegiatan pemangkasan, pengalaman kerja pemangkas merupakan sala satu faktor penting memperoleh hasil pangkasan yang baik dengan kerusakan cabang yang sedikit. Pengamatan keterampilan pemangkas berdasarkan lama kerja dilakukan terhadap pemangas yang bekerja $1-20$ tahun yang dibagi menjadi dua kelompok. Presentase kerusakan cabang berdasarkan lama kerja pemangkas tertera pada tabel 8 .

Tabel 8. Persentase kerusakan cabang berdasarkan lama kerja pemangkas

\begin{tabular}{cccc}
\hline $\begin{array}{c}\text { Lama Kerja } \\
\text { (Tahun) }\end{array}$ & $\Sigma$ Tenaga Kerja & $\Sigma$ Tanaman HK & \% Kerusakan Cabang \\
\hline$\leq 10$ & 5 & 5 & $5.23 \mathrm{tn}$ \\
$>10$ & 5 & 5 & $5.14 \mathrm{tn}$ \\
\hline
\end{tabular}

Sumber : Hasil Pengamatan Secara Langsung (Maret, 2013)

Keterangan : Angka yang diikuti huruf (tn) yang berbeda pada kolom yang sama menunjukkan

hasil yang tidak berbeda nyata pada uji t-student pada taraf $5 \%$ 
Hasil uji t persentase kerusakan cabang berdasarkan lama kerja menunjukkan hasil yang tidak berbeda nyata, sehingga bisa dilihat bahwa faktor lama kerja tenaga pemangkas tidak berpengaruh pada kegiatan pemangkasan.

Keterampilan Tenaga Kerja Pemangkas Berdasarkan Klasifikasi Lama Kerja. Pengamatan keterampilan tenaga pemangkas berdasarkan tingkat pendidikan dilakukan terhadap 10 orang tenaga pemangkas yang dibagi menjadi dua kelompok masing-masing 5 orang untuk tingkatan pendidikan TTSD (Tidak Tamat Sekolah Dasar), sedangkan 5 orang lainnya untuk tingkatan pendidikan SD (Sekolah Dasar). Presentase kerusakan cabang berdasarkan tingkat pendidikan tertera pada tabel 9 .

Tabel 9. Persentase kerusakan cabang berdasarkan tingkat pendidikan

\begin{tabular}{|c|c|c|c|}
\hline Tingkat Pendidikan & $\Sigma$ Tenaga Kerja & $\sum$ Tanaman HK & \% Kerusakan Cabang \\
\hline TTSD & 5 & 5 & 4.52 tn \\
\hline $\mathrm{SD}$ & 5 & 5 & $4.39 \mathrm{tn}$ \\
\hline Sumber & amatan Secara Lal & (Maret, 2013) & \\
\hline Keterangan & $\begin{array}{l}\text { g diikuti huruf ( } \mathrm{tn} \text { ) } \\
\text { tidak berbeda nyat }\end{array}$ & $\begin{array}{l}\text { erbeda pada kolon } \\
\text { jji t-student pada ta }\end{array}$ & menunjukkan \\
\hline
\end{tabular}

Hasil uji t persentase kerusakan cabang berdasarkan tingkat pendidikan menunjukkan hasil tidak berbeda nyata, sehingga sehingga bisa dilihat bahwa faktor latar belakang pendidikan tidak begitu berpengaruh dalam kegiatan pemangkasan.

\section{Pertumbuhan Tunas}

Pengamatan pertumbuhan tunas dilakukan di blok Bismo dan Argopuro dengan ketinggian tempat yang relatif sama $\pm 1300 \mathrm{~m} \mathrm{dpl}$. Pengamatan dimulai pada saat tunas berumur 5 MSP. Grafik pertumbuhan tunas mulai 5-8 MSP dapat dilihat pada Gambar 4.

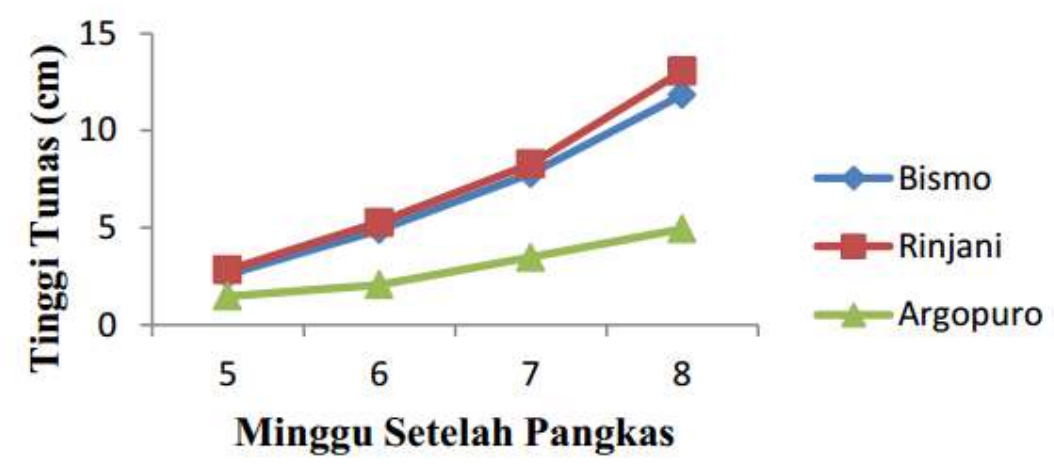

Gambar 4 Grafik pertumbuhan tunas

Berdasarkan Gambar 4 di atas, terdapat perbedaan kecepatan pertumbuhan tunas antara blok Bismo, Rinjani dan Argopuro. Perbedaan tersebut disebabkan oleh perbedaan jenis tanaman. blok Bismo menggunakan jenis tanaman dari klon campuran (TRI 2025), blok Rinjani menggunakan jenis tanaman dari klon Gambung, sedangkan blok Argopuro menggunakan jenis tanaman seedling. Perbedaan pertumbuhan tunas mulai terlihat pada 5 MSP. Kecepatan pertumbuhan tunas blok Bismo dan Rinjani lebih tinggi dibandingkan dengan blok Argopuro. Jenis tanaman yang berasal dari klon memiliki kecepatan pertumbuhan tunas yang lebih tinggi dibandingkan dengan tanaman yang berasal dari seedling.

\section{KESIMPULAN}

Kegiatan pemangkasan teh di unit perkebunan Bedakah pada umumnya berjalan dengan baik. Gilir pangkas yang ditetapkan sesuai dengan pedoman umur gilir pangkas berdasarkan letak tempat di atas permukaan laut. Pemangkasan memperhatikan produksi pucuk, apabila produksi pucuk dianggap stabil pada musim kemarau maka pelaksanaan pemangkasan dapat dilakukan $100 \%$ di semester I. pada gilir pangkas tahun ini semua blok melaksanakan pemangkasan dalam dua 
semester. Realisasi luas areal yang dipangkas dalam satu tahun tidak selalu sama dengan rencana yang telah ditetapkan sebesar $25 \%$. Berdasarkan data yang diperoleh dalam kurung waktu lima tahun realisasi pangkasan hanya 17.83 $\%$ dari luas areal tanaman menghasilkan.

Keterampilan dan pengalaman kerja dari pemangkas merupakan faktor yang penting dalam tercapainya kualitas pangkasan. Keterampilan pemangkas berdasarkan klasifikasi usia, lama kerja dan tingkat pendidikan tidak berpengaruh nyata terhadap kerusakan cabang atau hasil pangkasan. Dengan demikian, dapat disimpulkan bahwa keterampilan pemangkas di unit perkebunan Bedakah cukup baik.

\section{DAFTAR PUSTAKA}

[DITJENBUN] Direktorat Jenderal Perkebunan. 2012. Statistik Perkebunan Indonesia: Teh (Camellia sinensis) 2008 - 2012. Jakarta (ID) : Direktorat Jenderal Perkebunan, Departemen Pertanian.

Ghani, M.A. 2002. Buku Pintar Mandor : DasarDasar Budidaya Teh. Jakarta (ID): Penebar Swadaya.
Johan, M.E. 2006. Pengaruh istirahat petik pada pangkasan terhadap pertumbuhan tunas dan produktivitas jendangan. Jurnal Penelitian Teh dan Kina. 9 (3) : $63-68$.

PT Perkebunan Nusantara XI. 2005. Vademecum Budidaya Teh. Jakarta (ID) : PT Perkebunan XI.

Pusat Penelitan Teh dan Kina. 2006. Petunjuk Kultur Teknis Tanaman Teh. Edisi Ketiga. Bandung (ID) : Lembaga Riset Perkebunan Indonesia, Pusat Penelitian Teh dan Kina.

Setyamidjaja , D. 2000. TEH, Budidaya dan Pengolahan Pasca Panen. Yogyakarta (ID): Kanisius.

Sukasman. 1988. Pemangkasan pada Tanaman Teh Menghasilkan. Bandung (ID) : Prosiding Seminar Pemangkasan Teh. Balai Penelitian Teh dan Kina Gambung.

Suwarto, Octavianty, Y. 2010. Budidaya Tanaman Perkebunan Unggulan. Jakarta (ID): Penebar Swadaya. 